\title{
中国归化植物组成特征及其时空分布格局分析
}

\author{
许光耀 ${ }^{1}$ 李洪远 $^{*}$ 莫训强 $^{2}$ 孟伟庆 ${ }^{2}$ \\ ${ }^{1}$ 南开大学环境科学与工程学院, 天津 $300350 ;{ }^{2}$ 天津师范大学城市与环境科学学院, 天津 300382
}

摘 要 入侵植物是归化植物的子集, 归化是植物入侵的基本前提, 完整的归化植物清单有助于预测和预防植物入侵。该文 基于实地调查和资料收集, 对中国归化植物种类及分布进行统计, 结果表明, 当前中国共有归化植物112科578属1 099种, 约 $70 \%$ 为人为引入, 而美洲是其最大原产地，植物生活型以草本为主，分类学组成中菊科、禾本科、豆科最多。在空间尺度上，物 种多样性及密度均呈自东南沿海向西北内陆递减的趋势, 纬度和国内生产总值是其空间分布格局的主要驱动因素, 被殖民 史、植物园分布及调查次数在一定程度上影响空间分布格局; 在时间尺度上, 归化植物物种多样性当前正处在快速增长阶段 并可能持续20-30年, 社会经济发展、人为干扰、土地利用方式改变及全球变化是其主要驱动因素。该研究丰富了中国归化 植物的本底资料, 有助于了解外来植物入侵的形式与威胁, 并为外来植物综合管控或本地生物多样性保护提供依据。

关键词 生物入侵; 外来植物; 物种组成; 分布特征; 驱动因素

许光耀, 李洪远, 莫训强, 孟伟庆 (2019). 中国归化植物组成特征及其时空分布格局分析. 植物生态学报, 43, 601-610. DOI: 10.17521/cjpe.2019.0053

\section{Composition and spatial-temporal distribution of Chinese naturalized plants}

XU Guang-Yao ${ }^{1}$, LI Hong-Yuan ${ }^{1 *}$, MO Xun-Qiang ${ }^{2}$, and MENG Wei-Qing ${ }^{2}$

${ }^{1}$ College of Environmental Science and Engineering, Nankai University, Tianjin 300350, China; and ${ }^{2}$ College of Urban and Environmental Science, Tianjin Normal University, Tianjin 300382, China

\begin{abstract}
Aims Invasive plants are a subset of naturalized plants, and naturalization is a fundamental precondition for plant invasion and so compiling a complete inventory of naturalized alien species is necessary for predicting and hence preventing such invasion.

Methods Based on field investigations and various literature reports, we compiled a nationwide list of the naturalized plant species of China.

Important findings The results showed that there are 1099 naturalized plants belonging to 112 families and 578 genera in China, $70 \%$ of them were introduced intentionally and were of American origin, followed by those with European origins, herbs were prevalent among naturalized species. Compositae, Gramineae and Leguminosae were the three most dominant families. Spatially, species diversity and density decreased from the southeast coast to inland northwest. Latitude and gross domestic product is the primary driver of this pattern, however, colonial history, distribution of botanical gardens and the number of surveys may also affect formation. In temporal terms, species diversity is currently in a period of rapid growth and will continue for 20 to 30 years. Social and economic development, human disturbance, land use and global change are the main drivers. This study enriches the background information about naturalized plants and improves our knowledge on threats associated with plant invasions in China. The gained information can be used to provide arguments for efforts on control and management of alien plants or conservation of native biodiversity in the country.
\end{abstract}

Key words biological invasion; alien plants; species composition; distribution characteristics; driving factors

Xu GY, Li HY, Mo XQ, Meng WQ (2019). Composition and spatial-temporal distribution of Chinese naturalized plants. Chinese Journal of Plant Ecology, 43, 601-610. DOI: 10.17521/cjpe.2019.0053

栖息地丧失、生物入侵、传统化学污染及气候

合国《生物多样性公约》中提到: 美国、澳大利亚、 变化是当今全球四大环境问题(闵小玲等, 2012)。联

英国、南非、印度和巴西每年因为外来入侵种而蒙

收稿日期Received: 2019-03-12 接受日期Accepted: 2019-07-04

基金项目：天津市重大科技专项与工程(18ZXSZSF00200)。Supported by Science and Technology Major Project of Tianjin (18ZXSZSF00200).

* 通信作者Corresponding author (eialee@nankai.edu.cn) 
受的损失估计超过 1000 亿美元。植物入侵危害尤甚, 除巨额经济损失，还造成巨大的生态损失，全球荟 萃分析显示, 入侵植物能降低本地植物适合度 (41.7\%)、丰度(43.5\%)和多样性(50.7\%), 并会随着食 物链和营养级降低本地动物的适合度 $(16.5 \%)$ 、丰富 度(17.5\%)(Eviner et al., 2012)。

清晰的入侵物种本底资料是在国家层面上开展 后续科学研究和管理的重要基础。由于缺乏统一定 量的入侵认定标准, 研究人员极易将同一地区某种 外来植物判定为不同的入侵状态(逸生、归化或入 侵), 因而很难形成普遍认同的入侵植物名录 (Kleunen et al., 2015): 由于收录标准不同, 近年来 不同书籍或文献分别显示中国入侵植物种类为 420 种(Wu et al., 2010)、319种(Axmacher \& Sang, 2013)、 384种(Bai et al., 2013)、515种(间小玲等, 2014)。

与入侵概念相比, 相对更加二元化的归化概念 (外来物种能在自然条件下形成长期自我维持种群) 更加明确(Blackburn et al., 2011)。21世纪, 尤其是近 10 年, 越来越多的国家制定了使用标准化分类的归 化植物清单, 其中大多数研究集中在欧洲(Lambon et al., 2008; Medvecká et al., 2012)。最近van Kleunen 等(2015)建立全球归化植物数据库(GloNAF数据库) 并编制了全球归化植物清单(Pyšek et al., 2017), 其 中虽然包含中国地区，但由于数据收集、更新等问 题, 与中国当前实际情况存在较大的差异。据此, 我 们采用归化植物的概念, 统计了全国34个省(市、区) 的归化植物分类组成、原产地、生活型、引入途径, 并首次对其时空分布格局进行了分析, 以摸清中国 归化植物的本底资料, 为相关部门的深入研究、科 学普及以及综合管理和防治提供依据。

\section{1 研究方法}

\section{1 数据来源}

归化植物种类及分布数据分别来源于 《Flora of China》(FOC, http://foc.iplant.cn/)、在线植物志(FRPS, http://frps.iplant.cn)、自然标本馆(CFH, http://www. cfh.ac.cn/)、中国数字植物标本馆(CVH, http://www. cvh.ac.cn/)、中国植物图像库 (PPBC, http://ppbc. iplant.cn/)、中华本草 (http://www.zhongyaocai360. com/zhonghuabencao/)、各省植物志、全球外来归化 植物数据库 (gloNAF, https://glonaf.org/)等数据库及 其他文献资料。自然环境数据从中国气象网 (http://data.cma.cn)获得, 社会环境数据来自于中国 社会与经济发展数据库(http://tongji.cnki.net/kns55/ index.aspx)。

\section{2 数据处理与分析}

本文使用的外来植物、归化植物概念按照Pyšek 等(2004)的定义: 外来植物是指原产于中国以外的 植物; 归化植物是指没有人类直接干扰下, 能够长 期维持(通常在 10 年以上)种群自我更替的外来植 物。

根据文献资料统计、数据库查询, 形成归化植 物初始名单, 通过实地调查(主要在京津冀、山东等 地区)、标本数据分析对外来植物的归化状态进行判 定(外来、逸生或归化), 继而形成较完善的归化植物 名单。最后, 对名单中的植物进行名称及分类学标 准化并逐一确定生活型、原产地、引入途径、引入 时间及分布, 其中中文名称以FOC、台湾植物资讯 （台湾省单独分布且FOC未收录的物种, http://tai2. ntu.edu.tw/index.php)确定, 拉丁学名及植物科属分 类以The Plant List (TPL, http://www.theplantlist.org/) 确定。

用全国34个省市自治区作为空间单位探讨归化 植物分布格局。采用回归树分析确定归化植物丰富 度与自然/社会因素的关系, 回归树分析在 $\mathrm{R}$ 软件中 进行。

\section{2 结果}

\section{1 归化植物物种组成特征}

根据 1000 余篇文献, 50 余万份数字标本及图像 数据, 共统计到112科 578 属 1099 种归化植物, 其中 TPL收录1 088种(Accept), 未收录3种，未解决分类 问题(Unresolved) 8 种。另有 46 种植物为其他植物异 名(Synonym), 16种GloNAF记录的植物未找到分布 信息或归化证据，暂不收录(见附录I)。

\subsection{1 归化植物分类学}

从科的构成来看, 菊科、豆科、禾本科是中国 归化植物的主体, 3 科共计 399 种，占总种数的 $36.2 \%$, 其中菊科种类最多(146种)，其次是豆科(135种)，禾 本科位列第三(117种)。大于 10 种的科有 21 个(含 807 种)，5-9种的科为 25 个(含 163 种), 小于 5 种的科有 66 个, 其中单种科 31 个(图1)。

从属的角度分析, 物种数最多的属为茄属 (Solanum)共23种, 其次为大戟属(Euphorbia)共22种, 
苋属(Amaranthus)和番薯属(Ipomoea)各19种。大于 10 种的属有决明属(Senna，14种)、月见草属 (Oenothera, 12种)、车轴草属(Trifolium, 11种)、猪屎 豆属(Crotalaria, 11种)、相思树属(Acacia, 10种)、桉 属(Eucalyptus, 10种)(表1)。5-9种的属20个, 小于5 种的属 548 个, 其中单种属 373 个。

\subsection{2 归化植物原产地}

当前，外来植物原产地分析大多采用 TDWG (生物多样性信息标准, https://www.tdwg.org/)的大 洲分区体系, 在本研究中添加了出现频率较高的地 中海区域, 除10种起源不详的植物外, 中国归化植
物起源有以下类型：南/北美洲、温带/热带亚洲、地 中海区域、非洲、欧洲、太平洋岛屿、大洋洲、杂 交起源、栽培起源、古热带起源。归化植物的原产 地共计1307频次(在各省市自治区出现次数的总和), 其中原产于南美洲的物种最多, 为 400 频次 (约占 $30.6 \%$ ), 其后依次为北美洲 206 频次(约占 $15.76 \%$ )、 欧洲185频次(约占 $14.31 \%$ )、热带亚洲148频次(约占 $11.32 \%$ )、非洲146频次(约占11.17\%)、温带亚洲105 频次(约占 $8.03 \%$ )、地中海 47 频次、大洋洲 39 频次, 杂 交和栽培起源的植物共有 10 种, 古热带起源植物 4 种(图2)。

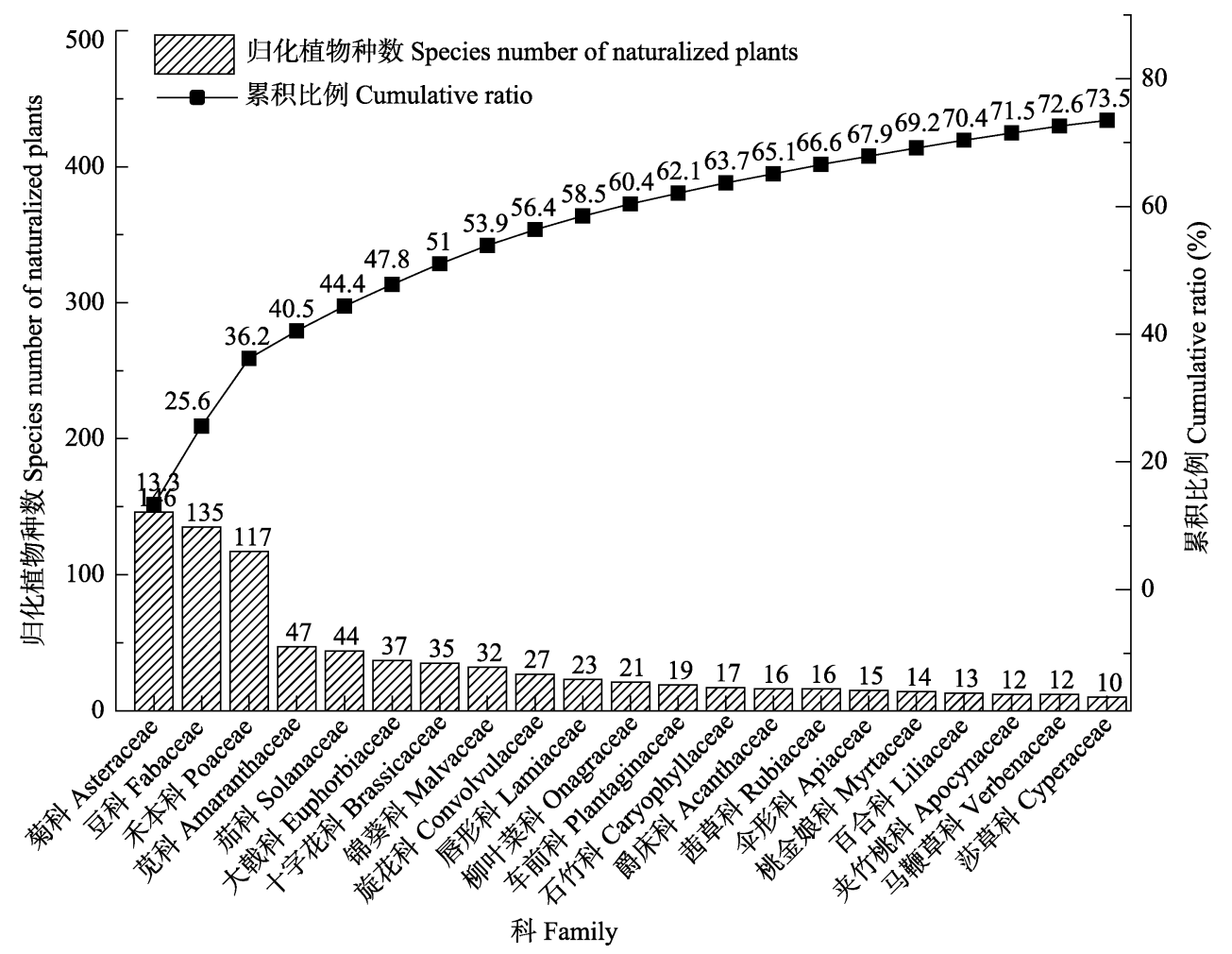

图1 中国归化植物主要科帕累托图。

Fig. 1 Pareto diagram of the main families of naturalized plants in China.

表1 中国归化植物主要属及其种数

Table 1 Main genera of naturalized plants and their species number in China

\begin{tabular}{|c|c|c|c|c|c|}
\hline 属 Genera & \begin{tabular}{c|c} 
种数 \\
Number of species
\end{tabular} & 属 Genera & $\begin{array}{c}\text { 种数 } \\
\text { Number of species } \\
\end{array}$ & 属 Genera & $\begin{array}{c}\text { 种数 } \\
\text { Number of species }\end{array}$ \\
\hline 茄属 Solanum & 23 & 雀稗属 Paspalum & 9 & 金纽扣属 Acmella & 6 \\
\hline 大戟属 Euphorbia & 22 & 飞蓬属 Erigeron & 9 & 含羞草属 Mimosa & 6 \\
\hline 苋属 Amaranthus & 19 & 莎草属 Cyperus & 8 & 独行菜属 Lepidium & 6 \\
\hline 番薯属 Ipomoea & 19 & 酢浆草属 Oxalis & 7 & 仙人掌属 Opuntia & 5 \\
\hline 决明属 Senna & 14 & 西番莲属 Passiflora & 7 & 婆婆纳属 Veronica & 5 \\
\hline 月见草属 Oenothera & 12 & 黑麦草属 Lolium & 7 & 龙舌兰属 Agave & 5 \\
\hline 猪屎豆属 Crotalaria & 11 & 松属 Pinus & 6 & 藜属 Chenopodium & 5 \\
\hline 车轴草属 Trifolium & 11 & 雀麦属 Bromus & 6 & 苼藜草属 Cenchrus & 5 \\
\hline 相思树属 Acacia & 10 & 莲子草属 Alternanthera & 6 & 山香属 Hyptis & 5 \\
\hline 桉属 Eucalyptus & 10 & 狼尾草属 Pennisetum & 6 & 白花菜属 Cleome & 5 \\
\hline
\end{tabular}




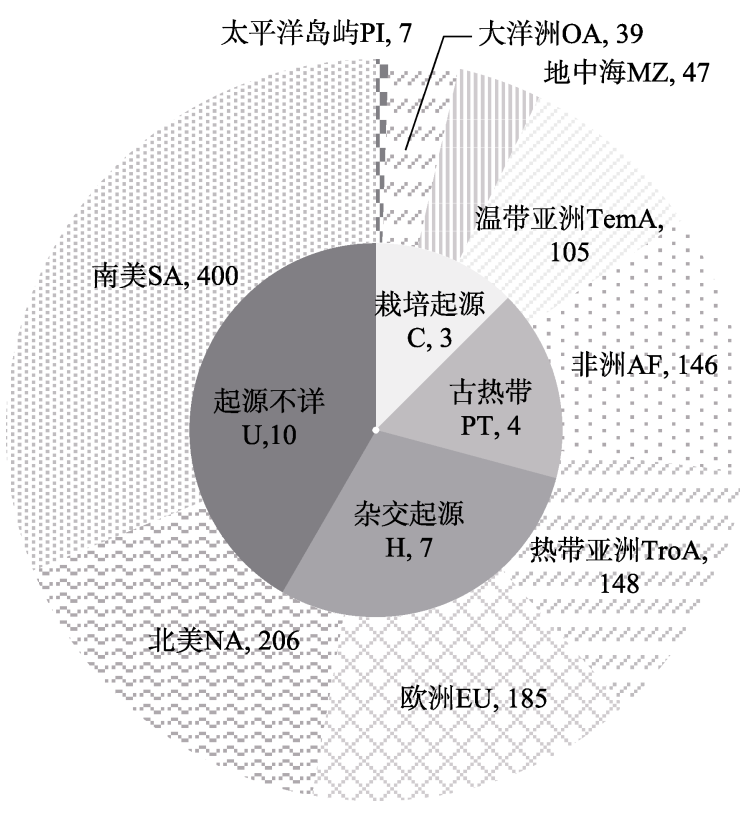

图2中国归化植物原产地分布图。

Fig. 2 Origin distribution of naturalized plants in China. AF, Africa; C, cultivate; EU, Europe; H, hybridization; MZ, Mediterranean Zone; NA, North America; OA, Oceania; PI, Pacific Islands; PT, palaeo tropics; SA, South America; TemA, Temperate Asia; TroA, Tropical Asia; U, unspecified.

\subsection{3 归化植物生活型}

根据归化植物的生活型统计, 木本植物 213 种, 占总数的 $19.40 \%$ ，其中乔木 101 种，灌木 100 种，木 质藤本植物 12 种。草质植物共 885 种, 占总种数的 $80.6 \%$, 其中草本植物 827 种, 草质藤本植物 57 种(包 含缠绕和攀缘植物), 寄生植物4种。在所有草本植 物中, 多年生植物(P)最多, 共396种, 占所有草本植 物的 $47.9 \%$ ，一年生植物(A) 306种，二年生植物(B) 为 25 种，一年/二年生植物(A/B)或一年/多年生植物
(A/P)植物分别有 55 种和 45 种(图3)。

\subsection{4 归化植物引入途径}

1099 种归化植物引入途径共计 1 132频次(某些 植物原产地不止一处), 其中自然杂交植物 1 种(引入 后的杂交植物, 黄松, 归化植物黑松Pinus thunbergii $\times$ 本地植物马尾松P. massoniana); 自然传入的仅 40 频次, 占总数的 $3.53 \%$; 人为传入 1091 频次, 占 总数的 $96.38 \%$, 其中园林绿化引入 417 频次，占总 数 $36.84 \%$, 无意引入 392 频次, 占总数的 $34.63 \%$, 食 用、牧草、材用、药用植物分别为 $97 、 68 、 61 、 56$ 频次，分别占总数的 $8.57 \% 、 6.01 \% 、 5.39 \% 、 4.95 \%$ (图4)。

\section{2 归化植物时空分布特征}

根据文献资料及标本数据, 我们确定了所有归 化植物的省级空间分布信息，并查询到其中955种 归化植物的首次引入时间(或首次记录时间), 占总 数的 $86.89 \%$, 其余 144 种未能查询到确切的引入时 间，但其中绝大多数应在19世纪之前引入。

\subsection{1 归化植物时间分布特征}

从时间分布上来看，自先秦至19世纪初，中国 归化植物累积种类大致趋于平稳, 只在公元 600 年 (隋朝)和 1000 年(北宋)经历两个较大涨幅, 但也只 分别增加12种和17种。1840年之前的 2000 余年间, 中国归化植物共累积 77-221 种，只占总数的 $7.01 \%-20.13 \%$ ，但自 1840 年开始，中国归化植物呈 爆炸式增长(图5), 百余年间, 归化植物已累积到上 千种。

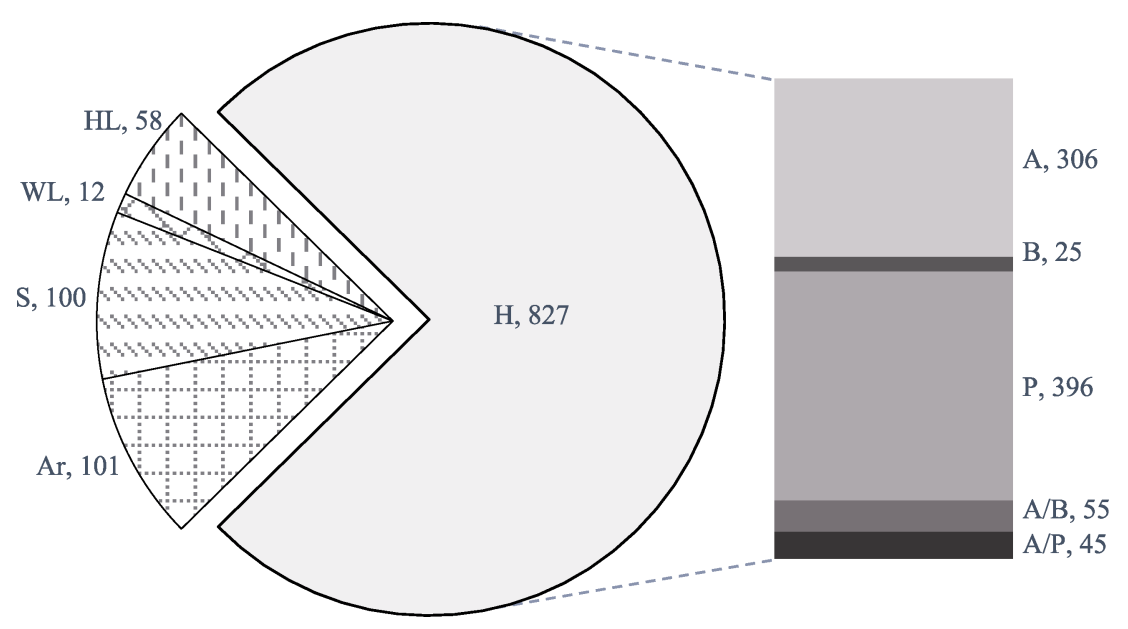

图3 中国归化植物生活型统计图。Ar, 乔木; HL, 草质藤本; S, 灌木; WL, 木质藤本; A, 一年生植物; B, 二年生植物; P, 多年 生植物; $\mathrm{A} / \mathrm{P}$, 一年/多年生植物; $\mathrm{A} / \mathrm{B}$, 一年/二年生植物。

Fig. 3 Life type statistics of naturalized plants in China. Ar, arbor; HL, herbaceous liane; S, shrub; WL, wood liane; A, annual plants; $\mathrm{B}$, biennial plants; $\mathrm{P}$, perennial plants; $\mathrm{A} / \mathrm{P}$, annual or perennial plants; $\mathrm{A} / \mathrm{B}$, annual or biennial plants. 


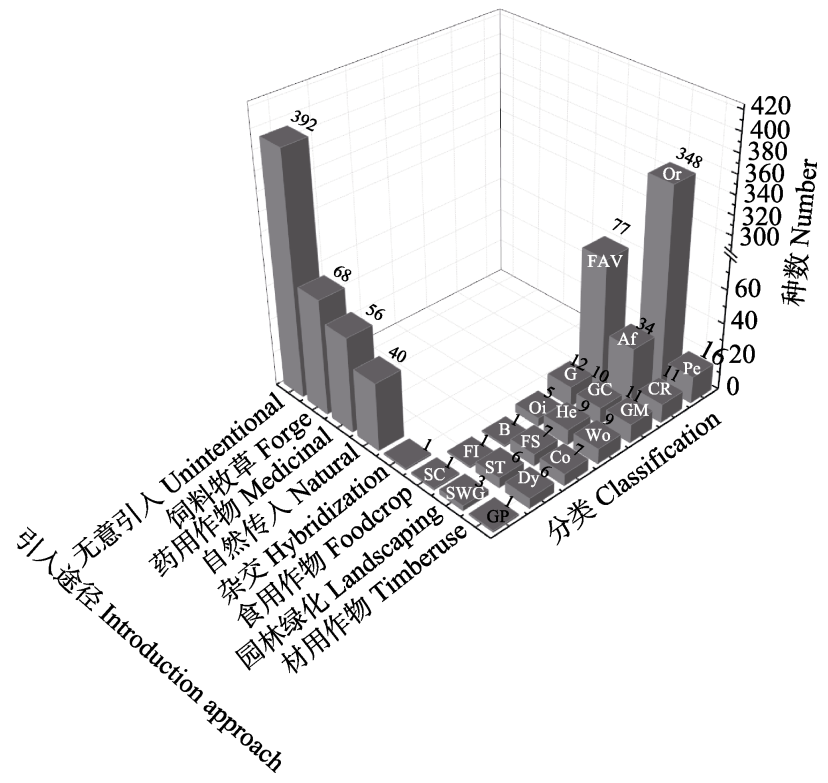

图4 中国归化植物引入途径图。Af, 造林; Be, 饮料; $\mathrm{Co}$, 胶 料; CR, 棉麻; Dy, 染料; FAV, 果蔬; FI, 吸食; FS, 花灌木; $\mathrm{GC}$, 地被; GM, 绿肥; GP, 基因库; Gr, 粮食; He, 绿篱; Oi, 油料; Or, 观赏; Pe, 香料 SC, 糖料; ST, 行道树; SWG, 水 土保持; Wo, 木料;。

Fig. 4 Introduction of naturalized plants in China. Af, afforestation; Be, beverage; Co, compound; CR, cotton ramie; Dy, dye; FAV, fruits and vegetables; FI, Food intake; FS, flowering shrubs; GC, ground cover; GM, green manure; GP, gene pool; Gr, grain; He, hedge; O, oil; Or, ornamental; Pe, perfume; SC, sugar crop; ST, street trees; SWG, soil and water conservation; Wo, wood.

\subsection{2 归化植物空间分布特征}

中国归化植物种类多样性呈自南向北、自东向 西、自沿海向内陆递减趋势(表2; 附录I)。归化植物 种数最多的是台湾, 共 628 种, 归化植物超过 500 种 的省份还有广东(572种)、广西(526种)和云南(518
种)。宁夏、青海、天津归化种类最少，分别为 106 、 144、157种。归化植物密度 (各省归化物种数与其面 积比值)空间分布自东南沿海向西北内陆呈递减趋 势，澳门、香港、上海最高，分居前三，每万平方公 里归化物种种数分别为 $72000 、 3200 、 506$ 种，其后 分别为北京(200种)、台湾(174.4种)、天津(127.4种)、 海南(125.9种), 内蒙古、西藏、青海最少, 分别为 1.4 种、1.6种、2.2种。

在所有归化植物中, 240 种仅在单一省(市、自治 区)分布, 283种在2-5个省有分布, 195种在6-10个省 有分布，114种在11-15个省有分布，90种在16-20个 省有分布，56种在21-25 个省有分布，116种在26个 (含)以上的省有分布，其中 46 种在全国各省均有 分布。

从归化植物科、属在中国的累积分布(各科或属 在各省出现次数的总和)来看, 菊科、豆科、禾本科 累积分布数量最多, 分别为 $1614 、 1410 、 939$ 种, 分 别占总数的 $15.1 \% 、 13.2 \% 、 8.8 \%$; 苋属、大戟属、 茄属累积分布最多，分别为333、269、246种。所有 科、属的种平均分布(各科或属累积分布数量与其物 种数的比值)分别为 $9.1 、 9.4$ (图6), 从各科(物种数多 于 6 种)、属(物种数多于 4 种)平均分布看, 葫芦科最 高, 为 20.56 , 其次为苋科(14.5)、茄科(14.3), 菊科、 豆科、禾本科分别为 $11.5 、 10.3 、 8.0$; 野踠豆属(Vicia) 最高, 为 28.8 , 其次为芸薹属 (Brassica, 25.8) 和鬼针 草属(Bidens, 25.3), 大戟属、茄属、苋属分别为 11.2 、 12.2、17.5。

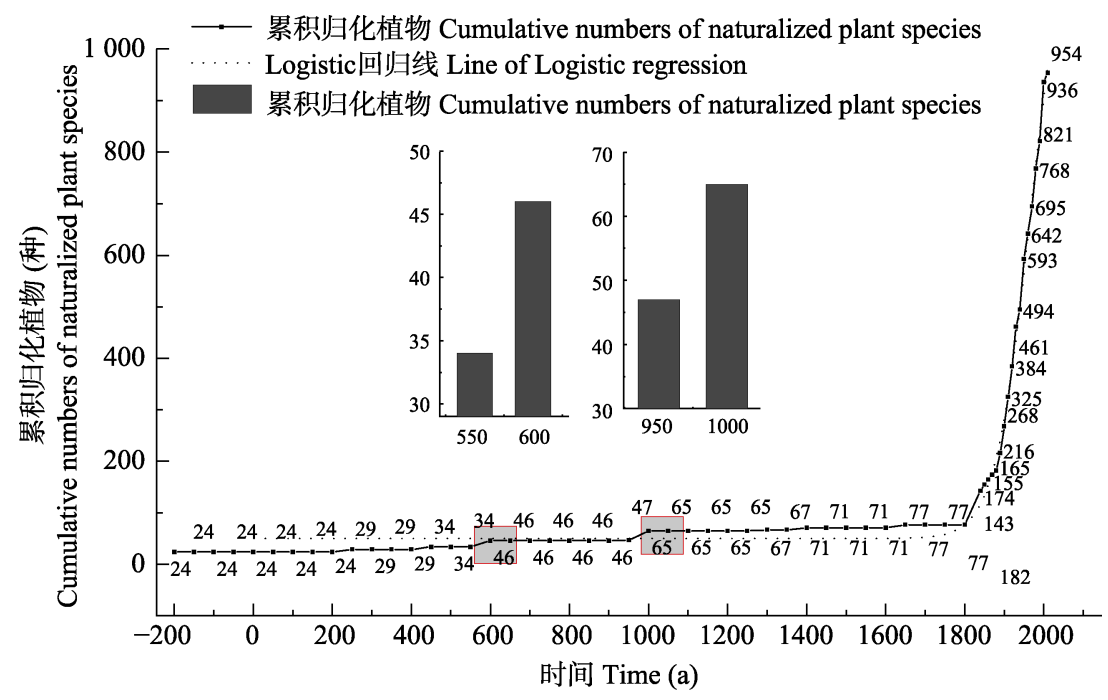

图5 中国归化植物种类随时间累积图。

Fig. 5 Accumulation of Chinese naturalized plants species over time. 

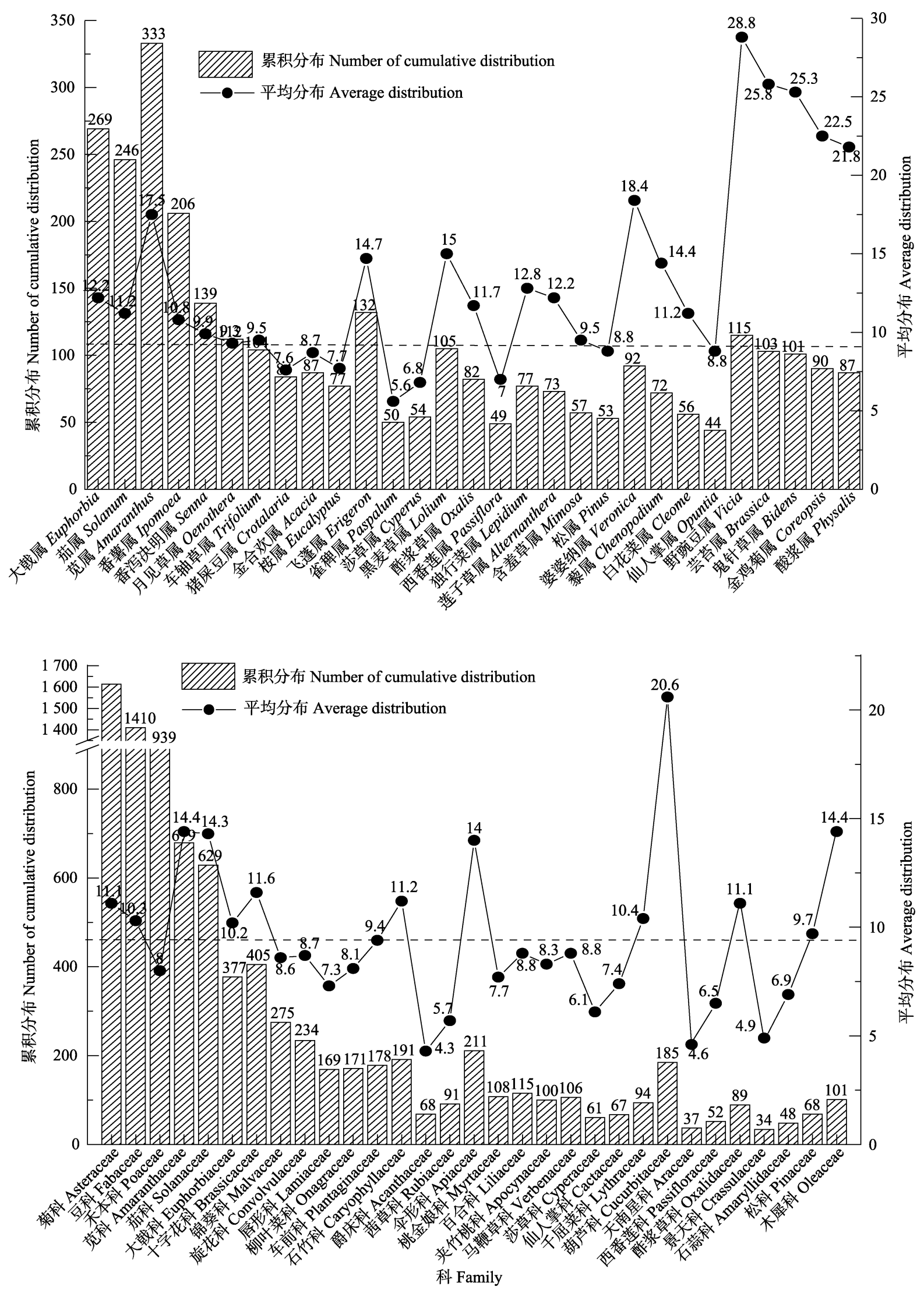

图6 中国归化植物主要属(上)、科(下)累积分布图。图中虚线表示所有属、科的种平均分布。

Fig. 6 Cumulation of main genera (above) and families (below) of naturalized plants in China. The dashed line indicates average distribution of each specie for all genus or family. 
表2 中国各省归化植物种类及密度

Table 2 Naturalized plant species and density in provinces of China

\begin{tabular}{|c|c|c|c|c|c|c|c|c|c|c|c|}
\hline $\begin{array}{l}\text { 区域 } \\
\text { Region }\end{array}$ & $\begin{array}{l}\text { 省份 } \\
\text { Province }\end{array}$ & $\begin{array}{l}\text { 种类 } \\
\text { NO. }\end{array}$ & $\begin{array}{l}\text { 排名 } \\
\text { Rank }\end{array}$ & $\begin{array}{c}\text { 密度 Density } \\
\text { (Species number. } \\
10000 \mathrm{~km}^{-2} \text { ) }\end{array}$ & $\begin{array}{l}\text { 排名 } \\
\text { Rank }\end{array}$ & $\begin{array}{l}\text { 区域 } \\
\text { Region }\end{array}$ & $\begin{array}{l}\text { 省份 } \\
\text { Province }\end{array}$ & $\begin{array}{l}\text { 种类 } \\
\text { NO. }\end{array}$ & $\begin{array}{l}\text { 排名 } \\
\text { Rank }\end{array}$ & $\begin{array}{c}\text { 密度 Density } \\
\text { (Species number } \\
10000 \mathrm{~km}^{-2} \text { ) }\end{array}$ & $\begin{array}{l}\text { 排名 } \\
\text { Rank }\end{array}$ \\
\hline \multirow{3}{*}{$\begin{array}{l}\text { 东北 } \\
\text { Northeast } \\
\text { China }\end{array}$} & 黑龙江 Heilongjiang & 189 & 28 & 4.2 & 30 & \multirow{7}{*}{$\begin{array}{l}\text { 华东 } \\
\text { East China }\end{array}$} & 山东 Shandong & 302 & 17 & 19.6 & 16 \\
\hline & 吉林 Jilin & 180 & 30 & 9.6 & 27 & & 江苏 Jiangsu & 388 & 8 & 37.8 & 10 \\
\hline & 辽宁 Liaoning & 276 & 22 & 18.9 & 18 & & 安徽 Anhui & 298 & 19 & 21.3 & 15 \\
\hline \multirow{5}{*}{$\begin{array}{l}\text { 华北 } \\
\text { North } \\
\text { China }\end{array}$} & 内蒙古 Nei Mongol & 162 & 31 & 1.4 & 34 & & 上海 Shanghai & 319 & 15 & 506.1 & 3 \\
\hline & 河北 Hebei & 246 & 24 & 13.1 & 26 & & 浙江 Zhejiang & 440 & 6 & 43.1 & 8 \\
\hline & 北京 Beijing & 336 & 12 & 204.8 & 4 & & 江西 Jiangxi & 385 & 9 & 23.1 & 13 \\
\hline & 天津 Tianjin & 144 & 33 & 127.0 & 6 & & 福建 Fujian & 493 & 5 & 40.6 & 9 \\
\hline & 山西 Shanxi & 223 & 25 & 14.3 & 24 & \multirow{5}{*}{$\begin{array}{l}\text { 西南 } \\
\text { Southwest } \\
\text { China }\end{array}$} & 四川 Sichuan & 355 & 10 & 7.4 & 28 \\
\hline 华中 & 河南 Henan & 291 & 20 & 17.4 & 19 & & 重庆 Chongqing & 286 & 21 & 34.8 & 11 \\
\hline \multirow{2}{*}{$\begin{array}{l}\text { Central } \\
\text { China }\end{array}$} & 湖北 Hubei & 306 & 16 & 16.5 & 20 & & 贵州 Guizhou & 333 & 13 & 18.9 & 17 \\
\hline & 湖南 Hunan & 326 & 14 & 15.4 & 22 & & 云南 Yunnan & 518 & 4 & 13.5 & 25 \\
\hline \multirow{6}{*}{$\begin{array}{l}\text { 华南 } \\
\text { South } \\
\text { China }\end{array}$} & 广东 Guangdong & 572 & 2 & 31.8 & 12 & & 西藏 Xizang & 202 & 26 & 1.6 & 33 \\
\hline & 广西 Guangxi & 526 & 3 & 22.3 & 14 & \multirow{5}{*}{\begin{tabular}{|l} 
西北 \\
Northwest \\
China
\end{tabular}} & 陕西 Shaanxi & 301 & 18 & 14.6 & 23 \\
\hline & 海南 Hainan & 428 & 7 & 124.9 & 7 & & 甘肃 Gansu & 198 & 27 & 4.4 & 29 \\
\hline & 香港 Hong Kong & 352 & 11 & 3200.3 & 2 & & 青海 Qinghai & 157 & 32 & 2.2 & 32 \\
\hline & 澳门 Macao & 180 & 29 & 72000.1 & 1 & & 宁夏 Ningxia & 106 & 34 & 16.0 & 21 \\
\hline & 台湾 Taiwan & 628 & 1 & 174.4 & 5 & & 新疆 Xinjiang & 268 & 23 & 2.3 & 31 \\
\hline
\end{tabular}

\section{3 归化植物空间分布的影响因素}

根据王国欢等(2017)的研究，选取纬度(LAT)、 年平均气温、年降水量作为关键自然环境因子, 选 取国内生产总值(GDP) 和铁路里程作为关键社会环 境因子(二者分别代表区域经济发展整体水平和交 通运输业发展程度)构建各省(港澳台除外)归化植物 丰富度分类回归树。回归树显示(图7), 中心纬度位 于 $30.18^{\circ} \mathrm{N}$ 以南的省份, 归化植物平均数量为 437.6 种; 以北的省份中, 经济发达地区归化物种数较高, 当GDP大于 1.81 万亿元时, 归化植物平均数量为 306.3种, 其余地区有192.2种。

\section{3 讨论}

\section{1 归化植物组成特征分析}

菊科、禾本科、豆科构成了中国归化植物的主

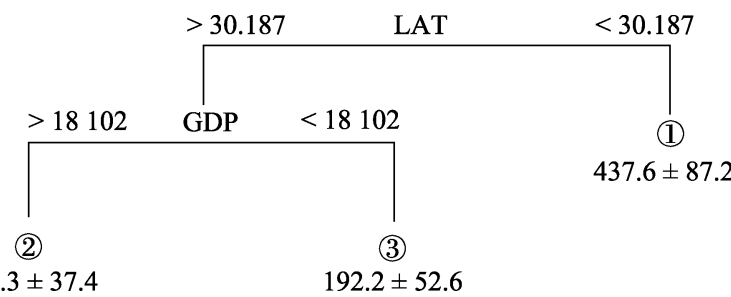

图7 归化植物多样性与自然、环境因子回归树。(1)(2)(3)为 各回归结点; LAT, 纬度; GDP, 国内生产总值。

Fig. 7 Regression tree of naturalized species richness and key social and environmental factors. (1)(2)(3), regression node; LAT, latitude; GDP, gross domestic product.
体，三者均是世界性分布的大科，TPL分别收录 32 913种、24 505种、11 554种，但各科归化比例(中 国除外的全球物种数与归化物种数之比)最高的三 科分别是百合科、睡莲科、泽泻科，归化比例分别 为 $41.9 \% 、 9.25 \% 、 4.85 \%$ 。百合科归化比例为 $41.9 \%$, 这个数值明显离群, 主要是由FOC与TPL分类标准 不同而导致的。睡莲科与泽泻科均为水生植物，相 对于陆生生境, 水环境更为均质、稳定, 不需要较多 的遗传多样性和较高的适应性, 睡莲科及泽泻科植 物就能通过克隆繁殖迅速归化(Gaskin et al., 2016)。

南北美洲是中国归化植物主要原产地, 影响归 化植物多样性的最根本原因是气候，无疑，南美与 中国南方(尤其是台湾、香港)的气候相似性更高，而 南方又是中国归化植物多样性的热点区域, 240 种单 一省(市、自治区)分布的归化植物中，仅台湾就有 144种。中国是北美最大的贸易伙伴国，贸易和人员 交流频繁使北美成为中国入侵植物最大的来源地 (鞠瑞亭等, 2012)。此外, 美洲不同的进化史使该地 植物能够从天敌逃逸、竞争力增强或化感作用中获 得更多优势(吴吴和丁建清, 2014)。

与入侵植物类似, 从生活型来看, 中国归化植 物中草本植物最多, 现代遗传学研究表明, 物种对 新环境的适应仅需要 20 代甚至更短的时间，同时草 本植物具有幼苗生长速度快、单位时间内开花次数 多、生活史短、繁殖能力强、种子数量多、个体小 
容易扩散及繁殖方式多样等特点, 这些生活史特征 使草本植物在竞争中具有明显的优势(间小玲等, 2014)。从引入途径看, 中国归化植物大多是有意引 入的, 无意引入仅占 $34.6 \%$ 。种源效应可能是产生这 种现象的最主要原因(许光耀等, 2018a), 有目的的 性状笁选和多次引入增大了物种库来源, 引入优势 性状的可能性更大(Buckley \& Catford, 2016), 此外, 作为牧草、饲料、蔬菜、观赏植物等有意引入的外 来植物, 与人类的关联度更强, 更易适应干扰日益 严重的环境。

\section{2 归化植物时空分布特征分析}

时间上, 16世纪前, 人类干扰程度低, 外来植物 传入和扩散路径较少, 且该时期中国归化植物主要 原产于欧亚大陆( $80 \%$ 以上), 相似的进化史使这些 地区的外来植物很难通过天敌逃逸获利。此外, 较 早归化的植物会占据空余生态位阻止其他植物归 化。自美洲大陆被发现(15世纪末)至19世纪初, 中国 长期闭关锁国，对外交流较少，传入植物自然不多。 19世纪至21世纪初, 中国归化植物种数呈爆炸式增 长, 短短百余年增长近 4 倍, 增加 800 余种, 累积达 到上千种。

自明末延续的小冰河极寒天气(年平均气温距 平可达 $-1.8{ }^{\circ} \mathrm{C}$ )带来大量空余生态位(王绍武和王日 昇，1990), 帝国主义列强在鸦片战争后陆续侵入中 国, 外来植物传入的数量急剧增加, 并迅速占领空 余生态位而归化。随着改革开放, 中国社会经济迅 速发展, 人为干扰加剧, 土地利用方式改变, 归化 速率进一步提升(Cabra-Rivas et al., 2016)。此外, 外 来植物能够搭乘全球气候变化的“快车”而迅速归化 (Waller et al., 2016), 而部分归化植物(入侵植物)又 能加剧本地生物多样性丧失、生态系统崩溃等全球 变化进程(许光耀等, 2018b)。回归分析(图5)显示, 中国归化物种随时间累积曲线符合 logistic 模型 $\left(R^{2}\right.$ $>0.99)$, 模型显示当前中国仍处于急速增长期, 并 将继续持续20-30年, 最终归化物种数量很可能超 过 1600 种。

空间上, 中国归化植物多样性和密度均呈自东 南沿海向西北内陆递减趋势, 南高北低、东高西低、 沿海高内陆低。大空间尺度下, 气候是归化的主要 笁选者, 回归树分析亦证明这点, 中国南部年平均 气温高、年降水量大、无结冰期, 且生境异质性更 高, 外来植物受环境限制较少, 因而更易归化。人类
干扰是归化的重要驱动力, 沿海城市的港口多, 交 通便利, 经济发展快, 与国外交流更频繁, 这同样 增加了植物归化的可能(Foxcroft et al., 2017)。

除经济、气候原因外, 以下原因也可能是形成 中国植物空间分布格局的原因: 首先是被殖民历史, 不论是归化植物多样性最高的台湾, 还是密度最高 的澳门、香港，均有长期的被殖民史，殖民地时期， 殖民者引入、驯化大量外来植物以“提升”用地生产 性或满足自身景观需求(Carruthers et al., 2011)。其 次是植物园分布, 中国植物园主要分布在东部, 特 别是沿海地区, 西北地区植物园数量极少。植物收 集、引种和驯化是植物园的重要任务, 国内每个植 物园的平均物种数在 3000 种左右, 西双版纳热带植 物园、广州华南植物园、北京植物园植物种类更是 超过 5000 种, 其中有 $1 / 3$ 是外来植物( He, 2002), 无 疑, 植物园所在地会成为植物归化的热点区域。最 后, 调查频次会影响结果准确性, 当前, 国内很多 省份都进行外来入侵植物调查, 部分市县级城市或 保护区也进行了本底调查, 但有些省份相关研究仍 是空白, 这无疑会影响统计结果。此外, 植物调查区 域极少是随机分布的, 植物标本采集活动往往受时 间、频率、交通等影响，这些问题增加了统计结果 的不确定性(Hyndman et al., 2015)。

\section{4 结论}

（1）中国当前共有归化植物112科578属1099种, 生活型以草本植物为主, 分类学组成中菊科、禾本 科、豆科最多, 美洲、欧洲、亚洲是主要原产地, 园 林绿化引入最多, 无意引入仅占归化植物总数的 $30 \%$ 左右。

(2) 当前中国归化植物种数正呈爆炸式增长, 并将持续20-30年, 最终归化物种数量很可能超过 1600 种。

(3) 中国归化植物多样性和密度呈自东南沿海 向西北内陆递减趋势, 经济、气候、被殖民史、植 物园分布和调查频次可能是导致该格局的原因。

\section{参考文献}

Axmacher JC, Sang W (2013). Plant invasions in China-Challenges and chances. PLOS ONE, 8, e64173. DOI: 10.1371/journal.pone.0064173.

Bai F, Chisholm R, Sang W, Dong M (2013). Spatial risk assessment of alien invasive plants in China. Environmental 
Science \& Technology, 47, 7624-7632.

Blackburn TM, Pyšek P, Bacher S, Carlton JT, Duncan RP, Jarošík V, Wilson JRU, Richardson DM (2011). A proposed unified framework for biological invasions. Trends in Ecology \& Evolution, 26, 333-339.

Buckley YM, Catford J (2016). Does the biogeographic origin of species matter? Ecological effects of native and non-native species and the use of origin to guide management. Journal of Ecology, 104, 4-17.

Cabra-Rivas I, Saldaña A, Castro-Díez P, Gallien L (2016). A multi-scale approach to identify invasion drivers and invaders' future dynamics. Biological Invasions, 18, 411-426.

Carruthers J, Robin L, Hattingh JP, Kull CA, Rangan H, van Wilgen BW (2011). A native at home and abroad: The history, politics, ethics and aesthetics of acacias. Diversity and Distributions, 17, 810-821.

Eviner VT, Garbach K, Baty JH, Hoskinson SA (2012). Measuring the effects of invasive plants on ecosystem services: Challenges and prospects. Invasive Plant Science and Management, 5, 125-136.

Foxcroft LC, Pyšek P, Richardson DM, Genovesi P, MacFadyen $S$ (2017). Plant invasion science in protected areas: Progress and priorities. Biological Invasions, 19, 1353-1378.

Gaskin JF, Pokorny ML, Mangold JM (2016). An unusual case of seed dispersal in an invasive aquatic; Yellow flag iris (Iris pseudacorus). Biological Invasions, 18, 2067-2075.

He SA (2002). Fifty years of botanical gardens in China. Acta Botanica Sinica, 44, 1123-1133.

Hyndman RJ, Mesgaran MB, Cousens RD (2015). Statistical issues with using herbarium data for the estimation of invasion lag-phases. Biological Invasions, 17, 3371-3381.

Ju RT, Li H, Shi ZR, Li B (2012). Progress of biological invasions research in China over the last decade. Biodiversity Science, 20, 581-611. [鞠瑞亭, 李慧, 石正人, 李博 (2012). 近十年中国生物入侵研究进展. 生物多样性, 20, 581-611.]

Lambdon PW, Pyšek P, Basnou C, Hejda M, Arianoutsou M, Essl F, Jarošík V, Pergl J, Winter M, Anastasiu P, Andriopoulos P, Bazos I, Brundu G, Celesti-Grapow L, Chassot P, Delipetrou P, Josefsson M, Kark S, Klotz S, Kokkoris Y, Kühn I, Marchante H, Perglová I, Pino J, Vilà M, Zikos A, Roy D, Hulme PE (2008). Alien flora of Europe: Species diversity, temporal trends, geographical patterns and research needs. Preslia, 80, 101-149.

Medvecká J, Kliment J, Májeková J, Halada L, Zaliberová M, Gojdičová E, Feráková V, Jarolímek I (2012). Inventory of the alien flora of Slovakia. Preslia, 84, 257-309.

Pyšek P, Pergl J, Essl F, Lenzner B, Dawson W, Kreft H, Weigelt P, Winter M, Kartesz J, Nishino M, Antonova LA, Barcelona JF, Cabesza FJ, Cárdenas D, Cárdenas-Toro J,
Castaño N, Chacón E, Chatelain C, Dullinger S, Ebel AL, Figueiredo E, Fuentes N, Genovesi P, Groom QJ, Henderson L, Inderjit, Kupriyanov A, Masciadri S, Maurel N, Meerman J, Morozova O, Moser D, Nickrent D, Nowak PM, Pagad S, Patzelt A, Pelser PB, Seebens H, Shu WS, Thomas J, Velayos M, Weber E, Wieringa JJ, Baptiste MP, Kleunen M (2017). Naturalized alien flora of the world: Species diversity, taxonomic and phylogenetic patterns, geographic distribution and global hotspots of plant invasion. Preslia, 89, 203-274.

Pyšek P, Richardson DM, Rejmánek M, Webster GL, Williamson M, Kirschner J (2004). Alien plants in checklists and floras: Towards better communication between taxonomists and ecologists. Taxon, 53, 131-143.

van Kleunen M, Dawson W, Essl F, Pergl J, Winter M, Weber E, Kreft H, Weigelt P, Kartesz J, Nishino M, Antonova LA, Barcelona JF, Cabezas FJ, Cárdenas D, CárdenasToro J, Castaño N, Chacón E, Chatelain C, Ebel AL, Figueiredo E, Fuentes N, Groom QJ, Henderson L, Inderjit, Kupriyanov A, Masciadri S, Meerman J, Morozova O, Moser D, Nickrent DL, Patzelt A, Pelser PB, Baptiste MP, Poopath M, Schulze M, Seebens H, Shu WS, Thomas J, Velayos M, Wieringa JJ, Pyšek P (2015). Global exchange and accumulation of non-native plants. Nature, 525, 100-103.

Waller DM, Mudrak EL, Amatangelo KL, Klionsky SM, Rogers DA (2016). Do associations between native and invasive plants provide signals of invasive impacts? Biological Invasions, 18, 3465-3480.

Wang GH, Bai F, Sang WG (2017). Spatial distribution of invasive alien animal and plant species and its influencing factors in China. Plant Science Journal, 35, 513-524. [王 国欢，白帆，桑卫国 (2017). 中国外来入侵生物的空间 分布格局及其影响因素. 植物科学学报, 35, 513-524.]

Wang SW, Wang RS (1990). Little ice age of China. Chinese Science Bulletin, (10), 769-772. [王绍武, 王日昇 (1990). 中国的小冰河期. 科学通报, (10), 769-772.]

Wu H, Ding JQ (2014). Recent progress in invasion ecology. Chinese Science Bulletin, 59, 438-448. [吴昊, 丁建清 (2014). 入侵生态学最新研究动态. 科学通报, 59, 438-448.]

Wu SH, Sun HT, Teng YC, Rejmánek M, Chaw SM, Yang TYA, Hsieh CF (2010). Patterns of plant invasions in China: Taxonomic, biogeographic, climatic approaches and anthropogenic effects. Biological Invasions, 12, 2179-2206.

Xu GY, Li HY, Meng WQ, MO XQ (2018a). Discrimination of "secondary invasion" and plant secondary invasion. Chinese Journal of Ecology, 37, 3780-3786. [许光耀, 李洪 远, 孟伟庆, 莫训强 (2018a). “Secondary Invasion”释义 辨析及植物继发入侵. 生态学杂志, 37, 3780-3786.]

Xu GY, Li HY, Mo XQ, Yang JZ (2018b). Research review on 
the advances of the invasive plants and the ecological effects of the related factors concerned. Journal of Safety and Environment, 18, 375-380. [许光耀, 李洪远, 莫训 强, 杨军中 (2018b). 入侵植物生态效应及其影响因素 研究进展. 安全与环境学报. 18, 375-380.]

Yan XL, Liu QR, Shou HY, Zeng XF, Zhang Y, Chen L, Liu Y, Ma HY, Qi SY, Ma JS (2014). The categorization and analysis on the geographic distribution patterns of Chinese alien invasive plants. Biodiversity Science, 22, 667-676. [闵小玲, 刘全儒, 寿海洋, 曾宪锋, 张勇, 陈丽, 刘演,
马海英, 齐淑艳, 马金双 (2014). 中国外来入侵植物的 等级划分与地理分布格局分析. 生物多样性, 22 , 667-676.]

Yan XL, Shou HY, Ma JS (2012). The problem and status of the alien invasive plants in China. Plant Diversity and Resources, 34, 287-313. [闵小玲, 寿海洋, 马金双 (2012). 中国外来入侵植物研究现状及存在的问题. 植物分类 与资源学报, 34, 287-313.]

特邀编委: 陈 涁 责任编辑: 李 敏 实习编辑: 赵 航

\section{附录I 中国归化植物名录及分布}

Supplement I List of naturalized species in China and their distribution http://www.plant-ecology.com/fileup/1005-264X/PDF/cjpe.2019.0053-S1.xlsx 